\title{
Anticancer Non-narcotic Opium Alkaloid Papaverine Suppresses Human Glioblastoma Cell Growth
}

\author{
MANA INADA $^{1}$, AKIRA SATO $^{1}$, MIKA SHINDO $^{1,2}$, YOHEI YAMAMOTO $^{3}$, \\ YASUHARU AKASAKI ${ }^{3}$, KOICHI ICHIMURA $^{4}$ and SEI-ICHI TANUMA ${ }^{1,5}$ \\ ${ }^{1}$ Department of Biochemistry, Faculty of Pharmaceutical Sciences, Tokyo University of Science, Noda, Japan; \\ ${ }^{2}$ National Cancer Center Hospital, Tokyo, Japan; \\ ${ }^{3}$ Department of Neurosurgery, Jikei University School of Medicine, Tokyo, Japan; \\ ${ }^{4}$ Division of Brain Tumor Translational Research, National Cancer Center Research Institute, Tokyo, Japan; \\ ${ }^{5}$ Department of Genomic Medicinal Science, Research Institute for Science and Technology, \\ Organization for Research Advancement, Tokyo University of Science, Noda, Japan
}

\begin{abstract}
Background: Glioblastoma (GBM) is the most aggressive type of primary malignant brain tumour. The interaction between high-mobility group box 1 (HMGB1) and receptor for advanced glycation end-products (RAGE) is important for tumour cell growth. Previously, we identified an anticancer candidate, papaverine, that inhibited the HMGB1-RAGE interaction. Materials and Methods: Our study assessed the anticancer effects of papaverine alone or in combination with temozolomide on U87MG and T98G human GBM cells using clonogenicity assays, as well as in a U87MG xenograft mouse model. The radiosensitizing efficacy of papaverine was measured based on the clonogenicity of T98G cells. Results: Papaverine significantly inhibited the clonogenicity of U87MG and T98G cells. Compared with single treatment, the combination of papaverine and temozolomide more highly suppressed the clonogenicity of T98G cells and delayed tumour growth in the U87MG xenograft mouse model. Furthermore, papaverine increased the radiosensitivity of T98G cells. Conclusion: Papaverine is a potential anticancer drug in GBM treatment.
\end{abstract}

Glioblastoma multiforme (GBM) is one of the most aggressive primary malignant brain tumours, with a median survival time of $\sim 14-15$ months after diagnosis (1-5). Conventional treatments for patients with newly diagnosed

Correspondence to: Akira Sato, Department of Biochemistry, Faculty of Pharmaceutical Sciences, Tokyo University of Science, 2641 Yamazaki, Noda, Chiba 278-8510, Japan. Tel/Fax: +81 471213620, e-mail: akirasat@rs.tus.ac.jp

Key Words: Papaverine, temozolomide, GBM, anti-cancer effect, radiosensitization.
GBM include surgery, radiotherapy, and chemotherapy with temozolomide. Temozolomide is the only standard chemotherapy available for GBM. It is the prodrug for an alkylating agent that transfers a methyl group to the O6, N7, and N3 positions of the purine bases of DNA. However, O6methylguanine-DNA methyltransferase (MGMT) directly repairs the main cytotoxic lesion caused by temozolomidemediated O6-guanine methylation. Therefore, MGMT activity may be the main mechanism underlying resistance to temozolomide $(3,4)$. In addition, mismatch repair and base excision repair contribute to resistance to temozolomide treatment $(3,4)$. Therefore, the discovery of next-generation anticancer drugs is important for improving the outcomes of GBM chemotherapy.

We previously evaluated the role of the interaction between high-mobility group box 1 (HMGB1) and receptor for advanced glycation end-products (RAGE) in facilitating tumour growth. HMGB1 is a non-histone DNA-binding nuclear protein that functions as an extracellular signalling molecule during inflammation, cell differentiation, cell migration, and tumour metastasis (6-9). HMGB1 has a high affinity for several receptors, including RAGE and toll-like receptors (TLR2, TLR4, and TLR9) (6-9). RAGE binds to multiple ligands including HMGB1, S100 family members, and amyloid- $\beta$ (6-9). RAGE activation has been implicated in inflammation, tumour cell growth, migration, and invasion (6-9). Previously, we identified papaverine, a non-narcotic opium alkaloid and an inhibitor of the HMGB1-RAGE interaction, using in silico drug design and drug repositioning (10). Moreover, papaverine was found to suppress RAGE-dependent cell proliferation, migration, and invasion in HT1080 human fibrosarcoma cells (11).

Papaverine, a non-narcotic opium alkaloid (Figure 1), is isolated from Papaver somniferum (12). Medicinal papaverine, which is used as a smooth-muscle relaxant in the 
treatment of vasospasm and erectile dysfunction, functions by inhibiting phosphodiesterase 10A (13-15). Papaverine reportedly shows selective anticancer effects on several types of tumour cells, including $\mathrm{LNCaP}(16,17)$ and $\mathrm{PC}-3$ prostate carcinoma (18); HT29 colorectal carcinoma (19); T47D (19), MCF-7, and MDA-MB-231 breast carcinoma (20); HT1080 fibrosarcoma (19); and HepG2 hepatocarcinoma cells (21). Benej et al. reported that papaverine radiosensitized A549 lung and EO771 breast tumour cells by targeting mitochondrial complex 1 (22). Recently, we demonstrated that papaverine suppressed the proliferation of human GBM temozolomide-sensitive U87MG and temozolomide-resistant T98G cells by inhibiting the interaction between HMGB1 and RAGE. In addition, papaverine reduced tumour volume in a human GBM U87MG xenograft mouse model (23).

In the present study, we examined the anticancer effects of papaverine alone or in combination with temozolomide in human GBM U87MG and T98G cells as well as in the U87MG xenograft mouse model.

\section{Materials and Methods}

Reagents. Papaverine hydrochloride was obtained from FUJIFILM Wako Pure Chemical Corporation (Osaka, Japan). Papaverine was stored as a $30-\mathrm{mM}$ stock solution in ultra-pure water at $-20^{\circ} \mathrm{C}$. Temozolomide was obtained from LKT Laboratories, Inc. (St. Paul, MN, USA) and stored as a $150-\mathrm{mM}$ stock solution in dimethyl sulphoxide (SigmaAldrich; Merck KGaA, Darmstadt, Germany) at $-20^{\circ} \mathrm{C}$.

Cell culture. Human GBM U87MG and T98G cell lines were cultured as previously described (23). Briefly, U87MG and T98G cells were cultured in E-MEM and RPMI-1640, respectively, supplemented with $10 \%$ heat-inactivated foetal bovine serum, 100 units $/ \mathrm{ml}$ penicillin, and $100 \mu \mathrm{g} / \mathrm{ml}$ streptomycin. Cells were grown in an incubator at $37^{\circ} \mathrm{C}$ with $5 \% \mathrm{CO}_{2}$ at $100 \%$ relative humidity.

Colony-formation assay. Colony-formation assays were performed as previously described $(24,25)$. T98G Human GBM cells were dissociated using AccuMax (NACALAI TESQUE INC., Nijo Karasuma, Kyoto, Japan), suspended in medium, seeded into 6-well plates (200 cells per well) in triplicate, and incubated overnight. U87MG cells were dissociated using accutase (NACALAI TESQUE INC., Nijo Karasuma, Kyoto, Japan), suspended in medium, seeded onto poly-L-lysine coated 6-well plates (400 cells per well) in triplicate, and incubated overnight. T98G cells were then treated with papaverine $(0.3,1,3,10$, and $30 \mu \mathrm{M})$ or temozolomide $(10$, $30,100,300$, and $1000 \mu \mathrm{M})$. U87MG cells were then treated with papaverine $(1,3,10,30$, and $100 \mu \mathrm{M})$ or temozolomide $(10,30$, $100,300$, and $1000 \mu \mathrm{M})$. Dimethyl sulfoxide (DMSO) and ultrapure water were used as controls. After incubation for 10 days, the cells were fixed with a $4 \%$ formaldehyde-phosphate-buffered saline (PBS) solution and stained with $0.1 \%$ (w/v) crystal violet. Colonies on the well were counted.

Gamma-ray irradiation. Gamma $(\gamma)$-ray irradiation was performed as previously described (25-27). T98G cells were $\gamma$-irradiated to different doses using a Cs137 Gammacells 40 Exactor (Best

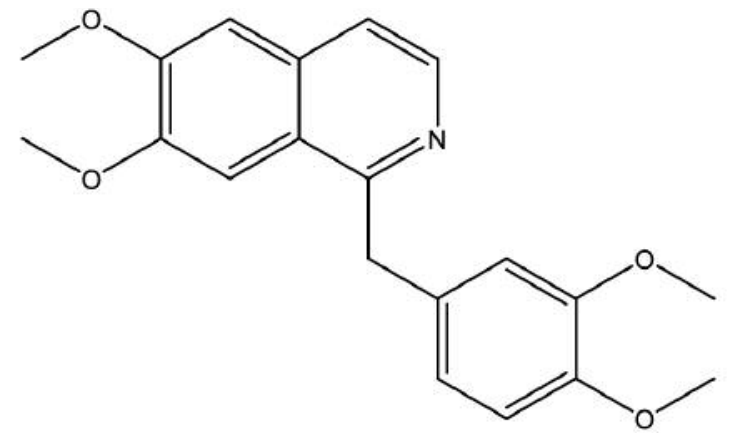

Figure 1. Chemical structure of the non-narcotic opium alkaloid papaverine.

Theratronics, Ltd., Kanata, Ontario, Canada) at a $\gamma$-ray irradiation dose rate of $0.777 \mathrm{~Gy} / \mathrm{min}$.

U87MG human GBM xenograft mouse model. All animal studies were approved by the Animal Experimental Committee at the Tokyo University of Science (TUS) and performed in accordance with the TUS Guidelines for Animal Experiments (\#Y16034 and \#Y15052). These requirements are in accordance with the ethical guidelines for experimental animals in Japan. The animals were housed at $23^{\circ} \mathrm{C} \pm 2^{\circ} \mathrm{C}$ under specific pathogen-free conditions with a $12 / 12 \mathrm{~h}$ light/dark cycle and provided a standard diet and water ad libitum. For heterotrophic/subcutaneous xenografts, $1 \times 10^{6}$ U87MG cells resuspended in $100 \mu \mathrm{l}$ PBS were subcutaneously injected into the right leg of 5-week-old male BALB/c nude mice (weight, 20-22 g; $\mathrm{n}=5$ ) (CLEA Japan, Inc., Tokyo, Japan). There were 5 mice in each treatment group. Before inoculation with the tumour cells, mice were anaesthetized with isoflurane (Escain ${ }^{\circledR}$ inhalation anaesthesia liquid $1 \mathrm{ml} / \mathrm{ml}$, Pfizer Inc, NY, USA); papaverine was diluted in normal saline. After 7-10 days of inoculation, papaverine (40 $\mathrm{mg} / \mathrm{kg}$ ) or saline (vehicle control, solvent alone) was administered intraperitoneally twice a day for 4 days ( $n=5$ per group). Temozolomide $(5 \mathrm{mg} / \mathrm{kg}$ ) or 1:3 DMSO/saline solution (vehicle control) was administered intraperitoneally once a day for 4 days $(\mathrm{n}=5$ mice per treatment group). Tumour volume (V) was measured once every 3-4 days using the following formula: $V=a b^{2} / 2$ (where $a$ and $b$ were the long and short diameters of the tumour, respectively). Mice were euthanized by isoflurane inhalation followed by cervical dislocation at the endpoint stage. In animal experiments, humane endpoint criteria were defined as follows: tumour burden $>10 \%$ of body weight, tumour volume $>2,000 \mathrm{~mm}^{3}$, or tumour largest dimension $>20 \mathrm{~mm}$.

Statistical analysis. All data are presented as mean and standard deviation. Significant differences among groups were assessed using the Student's $t$-test. Differences with $p<0.05$ were considered statistically significant.

\section{Results}

We previously investigated the anticancer activity of papaverine in several types of tumour cells, including GBM cells $(11,23)$. We evaluated the anticancer effects of 
A

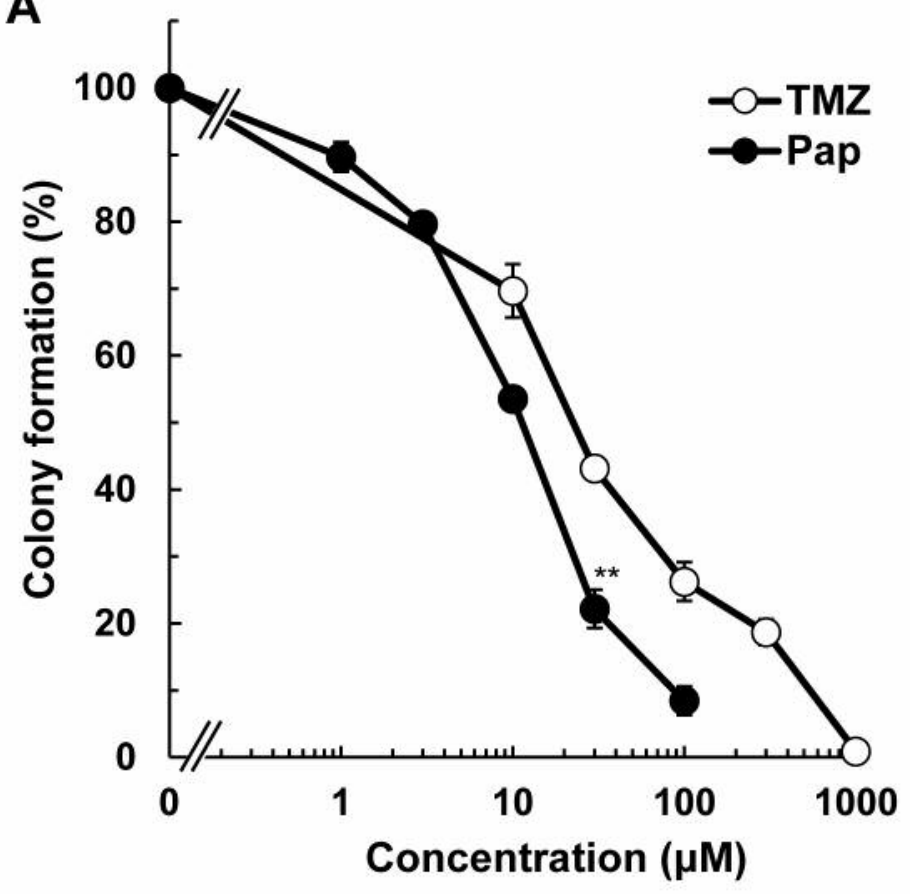

B
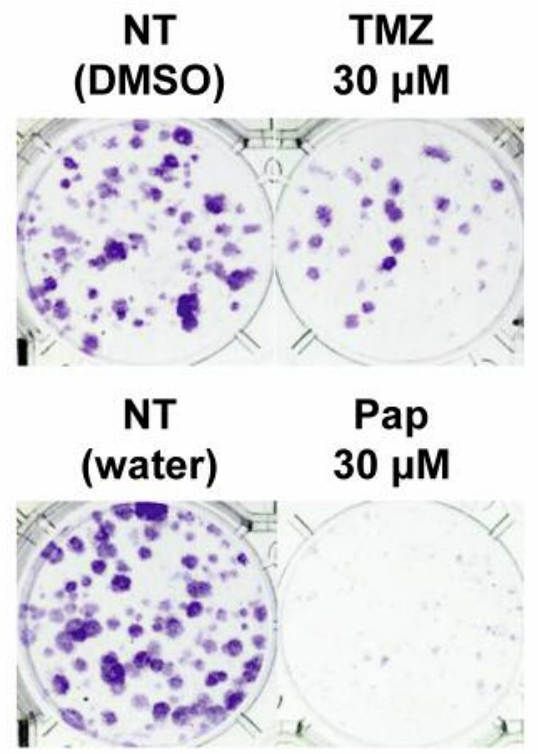

C
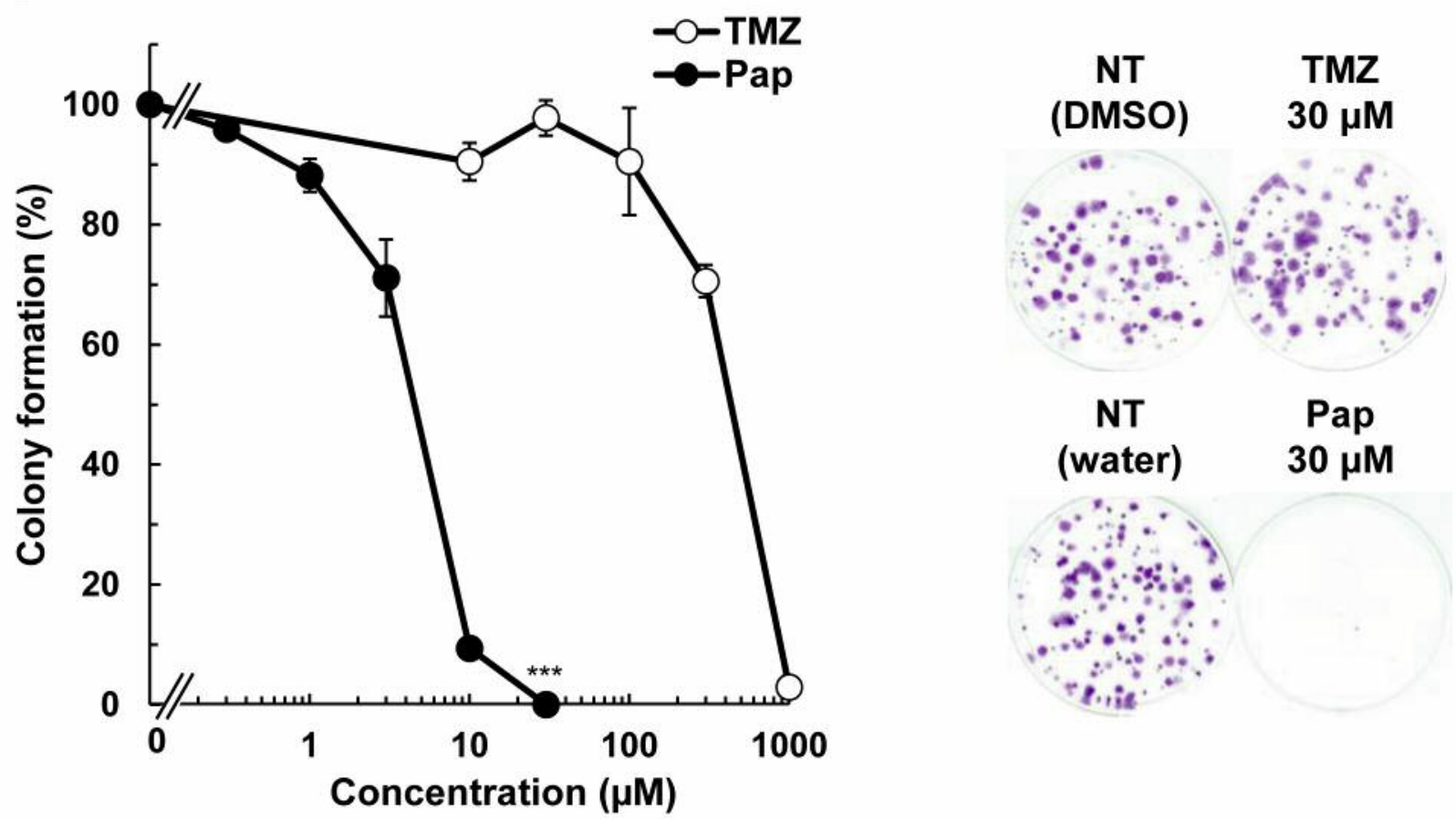

Figure 2. Anticancer effects of papaverine (Pap) in human glioblastoma (GBM) cells. A: Clonogenecity of U87MG human GBM cells after 10 days of treatment with papaverine and temozolomide (TMZ). Results are the average of three independent experiments performed in duplicate with error bars showing $\pm S E$. ${ }^{*} p<0.05$ (Pap at $30 \mu M v s . T M Z$ at $30 \mu M$ ). B: Drug sensitivity of U87MG cells was obtained from the colony-formation assay. Cells were treated with $30 \mu \mathrm{M}$ temozolomide or papaverine and incubated for 10 days. C: Clonogenecity of T98G cells after 10 days of treatment with papaverine and temozolomide. Results are the average of three independent experiments with error bars showing $\pm S E$ (triplicates). $* * * p<0.001$ (Pap at $30 \mu M$ vs. TMZ at $30 \mu M$ ). D: Drug sensitivities of T98G cells were obtained from the colony-formation assay. Cells were treated with 30 $\mu M T M Z$ or papaverine and incubated for 10 days. DMSO: Dimethyl sulfoxide; NT: Solvent alone (DMSO or water). 


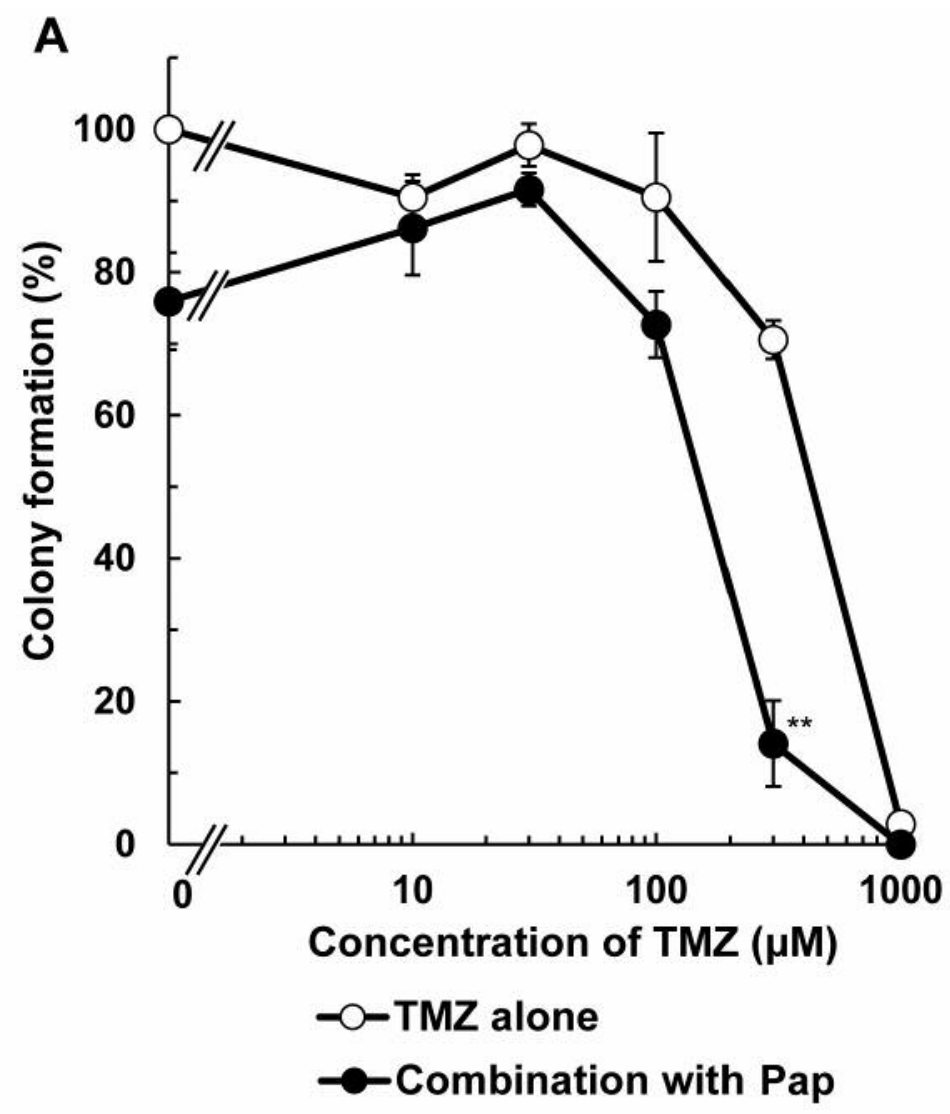

B Concentration of TMZ $(\mu \mathrm{M})$

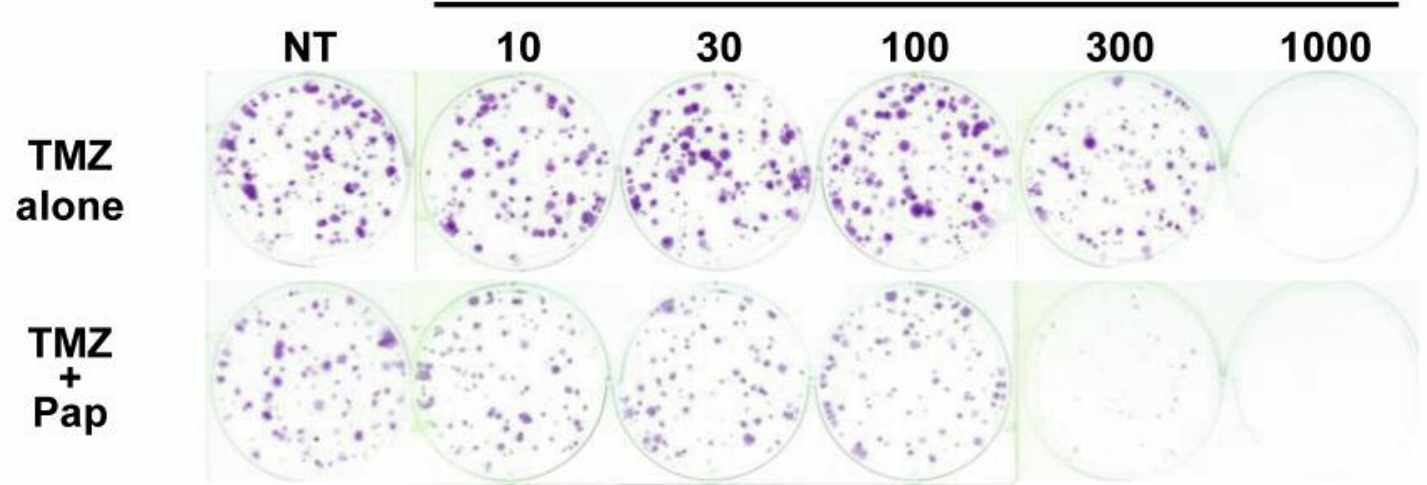

Figure 3. Anticancer effects of papaverine (Pap) and temozolomide (TMZ) combination therapy in T98G human glioblastoma (GBM) cells. A: Clonogenicity of T98G human GBM cells after 10 days of combination treatment with papaverine and temozolomide or temozolomide alone. Results are the average of two independent experiments with error bars showing $\pm S E$ in triplicates. ${ }^{*} p<0.05$ (TMZ alone vs. Pap $+T M Z$ at $300 \mu M$ TMZ). B: Drug sensitivity of $T 98 G$ cells was obtained from the colony-formation assay. Cells were treated with $30 \mu \mathrm{M}$ temozolomide or papaverine and incubated for 10 days.

papaverine in temozolomide-sensitive (MGMT-negative) U87MG and temozolomide-resistant (MGMT-positive) T98G cells using a WST-8 assay. The $50 \%$ effective concentration $\left(\mathrm{EC}_{50}\right)$ values for papaverine were 29 and $40 \mu \mathrm{M}$ in U87MG and $\mathrm{T} 98 \mathrm{G}$ cells, respectively (23) Conversely, the $\mathrm{EC}_{50}$ values for temozolomide were 42 and $390 \mu \mathrm{M}$ in U87MG and T98G cells, respectively (23). Papaverine inhibited the clonogenicity of U87MG $\left(\mathrm{EC}_{50}=11 \mu \mathrm{M}\right)$ and temozolomide- 
A

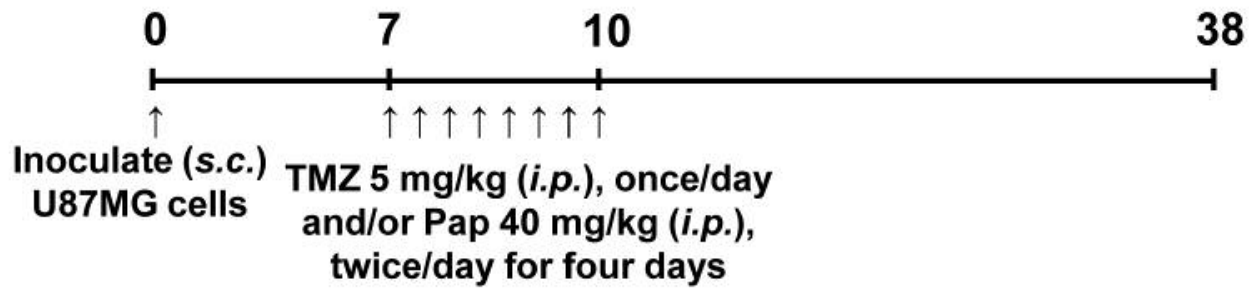

B
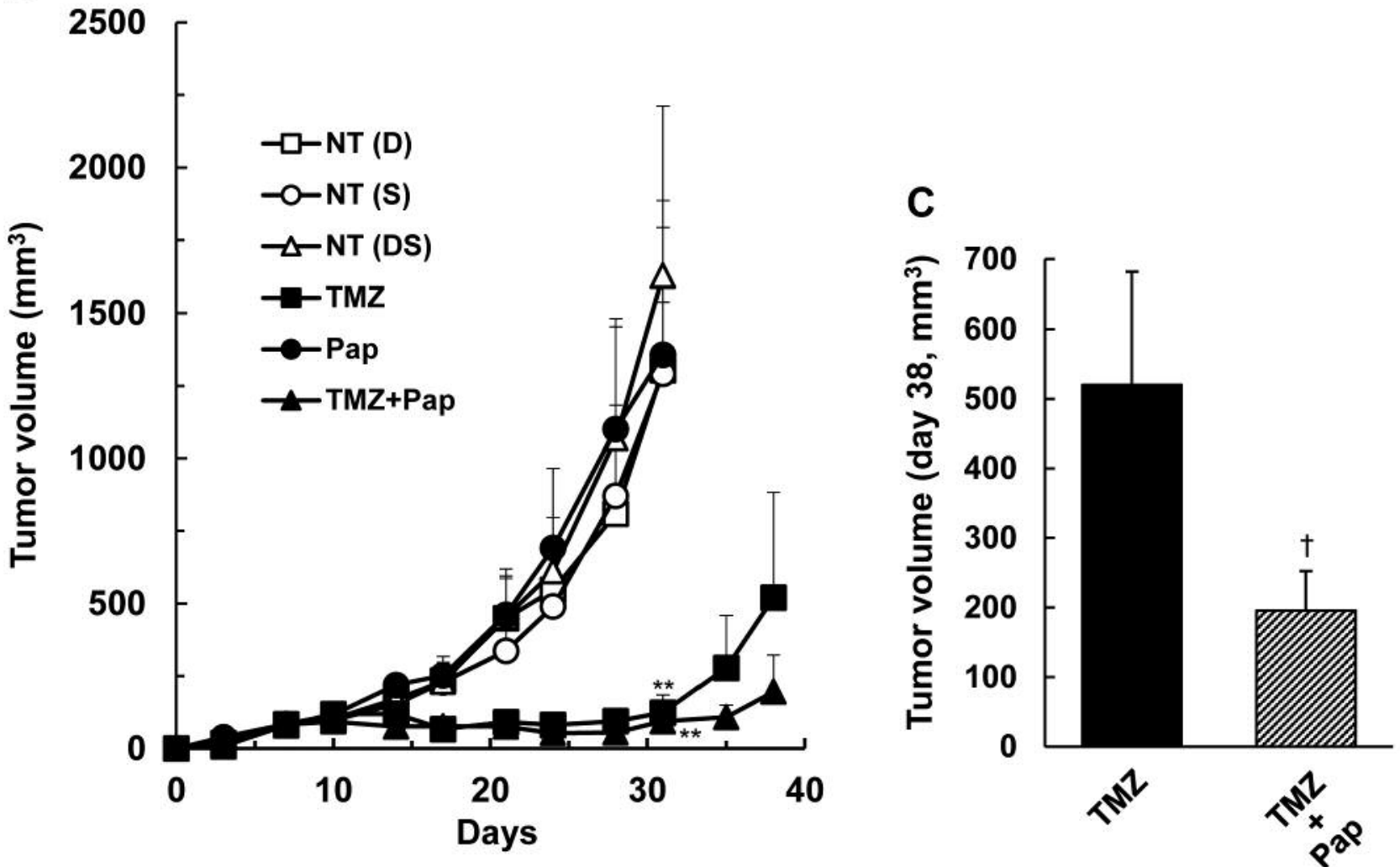

Figure 4. Anticancer effects of papaverine (Pap) and temozolomide (TMZ) combination therapy in a xenograft mouse model of human glioblastoma $(G B M)$. A: Experimental schedule. B: In order to assess the effects of papaverine monotherapy, and temozolomide and papaverine combination therapy in a xenograft model, $1 \times 10^{6}$ U87MG human GBM cells were subcutaneously injected into the right leg of 5-week-old male BALB/c nude mice. Seven days after inoculation, five mice per group were treated with papaverine (40 $\mathrm{mg} / \mathrm{kg}$; Pap) or saline [vehicle control, solvent alone; $\mathrm{NT}$ (S)] twice a day for 4 days or temozolomide ( $5 \mathrm{mg} / \mathrm{kg}$; TMZ) or DMSO/saline [vehicle control, solvent alone; NT (D)] once a day for 4 days via i.p. administration. For combination therapy, mice were treated with papaverine (40 $\mathrm{mg} / \mathrm{kg}$, twice a day) and temozolomide (5 mg/kg, once a day) or solvent alone for 4 days via i.p. administration. Tumour volume was measured once every 3-4 days and was calculated as described in the Materials and Methods section. Results are the averages for groups of five mice each with error bars showing $\pm S E .{ }^{* *} p<0.05[N T(D) v s . T M Z$ and NT(DS) vs. TMZ+Pap at day 31]. C: Tumour volumes following temozolomide monotherapy and combination therapy with papaverine and temozolomide in this xenograft model on day 38. Results are the averages for groups of five mice each with error bars showing $\pm S E$. ${ }^{\dagger} p>0.05$ (TMZ vs. TMZ+Pap).

resistant $\mathrm{T} 98 \mathrm{G}$ GBM cells $\left(\mathrm{EC}_{50}=4.5 \mu \mathrm{M}\right)$ in a dosedependent manner. Temozolomide yielded $\mathrm{EC}_{50}$ values of 23 and $430 \mu \mathrm{M}$ against U87MG and T98G cells, respectively (Figure 2). Since the clonogenicity of GBM U87MG cells was very low, we evaluated the anticancer effect of papaverine in U87MG cells using the colony-formation assay on poly-L-lysine coated plates. In addition, we assessed the effects the combination of papaverine and temozolomide on the clonogenicity of T98G cells. The addition of papaverine ( $2 \mu \mathrm{M}=\mathrm{EC}_{20}$ ) significantly enhanced the anticancer effects of temozolomide in $\mathrm{T} 98 \mathrm{G}$ cells. The $\mathrm{EC}_{50}$ for temozolomide was $430 \mu \mathrm{M}$ when used alone and $150 \mu \mathrm{M}$ when used in 
combination with papaverine (Figure 3). These findings suggest that papaverine enhances the anticancer effects of temozolomide in T98G GBM cells.

The in vivo anticancer activity of papaverine in combination with temozolomide was measured in male BALB/c nude mice bearing U87MG GBM xenografts (Figure 4A). The tumour volume significantly decreased after treatment with temozolomide alone (5 mg/kg, i.p., once/day for 4 days) as well as after combination treatment with temozolomide $(5 \mathrm{mg} / \mathrm{kg}$, i.p., once/day for 4 days) and papaverine $(40 \mathrm{mg} / \mathrm{kg}$, i.p., twice/day for 4 days) compared with that after the control treatment and treatment with papaverine alone $(40 \mathrm{mg} / \mathrm{kg}$, i.p. twice/day for 4 days). Combined treatment with temozolomide and papaverine was the most effective in inhibiting tumour growth (Figure 4B). At the end of the study period (31 days after treatment, i.e., 38 days after tumour implantation), there was an approximately $62 \%$ reduction in mean tumour volume following combination treatment with temozolomide and papaverine $\left(\right.$ mean $\left.\pm \mathrm{SE}=196 \pm 57 \mathrm{~mm}^{3}\right)$ compared with treatment with temozolomide alone $\left(\right.$ mean $\left.\pm \mathrm{SE}=520 \pm 162 \mathrm{~mm}^{3}\right)$. These data indicate that while papaverine alone did not suppress tumour growth in vivo, combination therapy with temozolomide and papaverine was more effective in suppressing in vivo tumour growth than temozolomide alone in the U87MG xenograft model. This finding suggests that papaverine can be used in combination with temozolomide for GBM treatment.

We evaluated the radiosensitizing effect of papaverine in GBM cells by evaluating the sensitivity of T98G cells to $\gamma$ ray irradiation following treatment with papaverine $\left(\mathrm{EC}_{25}=3.1 \mu \mathrm{M}\right)$ or temozolomide $\left(\mathrm{EC}_{25}=230 \mu \mathrm{M}\right)$ (Figure 5). While the $37 \%$ sensitizer enhancement ratio (SER37) for $\gamma$ ray irradiation with papaverine was 1.28 , it was 1.03 for that with temozolomide. Papaverine treatment significantly enhanced the $\gamma$-ray irradiation-induced loss of clonogenicity of T98G cells compared with temozolomide treatment. These data indicate that papaverine is a potential drug that may be useful in radiotherapy of GBM.

\section{Discussion}

Papaverine, a smooth muscle relaxant, is an opium alkaloid used for preventing intraoperative vasospasm during craniotomy (e.g. subarachnoid haemorrhage) (28-30). We identified papaverine as an inhibitor of the interaction between HMGB1 and RAGE using a unique in silico drug design system and a drug repositioning approach $(10,11,23)$. Moreover, we demonstrated that papaverine inhibits the proliferation of U87MG and T98G GBM cells. In addition, papaverine dramatically suppressed tumour growth in a human GBM U87MG xenograft mouse model (23). In this study, we found that papaverine significantly suppressed the clonogenicity of temozolomide-sensitive U87MG and temozolomide-resistant T98G GBM cells (Figure 2). In
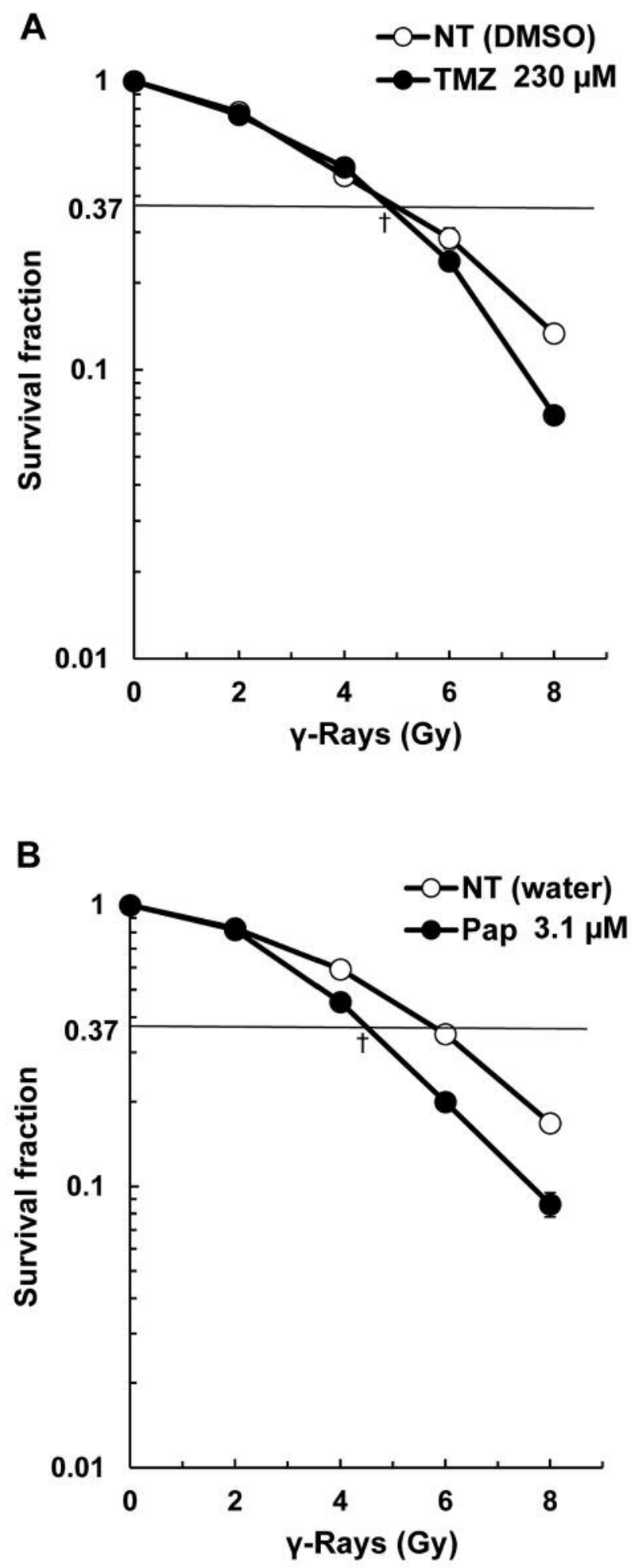

Figure 5. Radiosensitization of T98G human glioblastoma (GBM) cells by papaverine (Pap). Clonogenicity of T98G GBM cells was assessed following $\gamma$-ray irradiation and treatment with temozolomide (TMZ) (A) or papaverine (B) for 10 days. Results are the average of three independent experiments with error bars showing $\pm S E$ in triplicates. $\dagger p>0.05$ (NT vs. TMZ and NT vs. Pap at SER37). 
addition, combination treatment with temozolomide and papaverine suppressed the clonogenicity of T98G GBM cells (Figure 3) and tumour growth in the U87MG xenograft mouse model. This combination treatment was more effective than temozolomide or papaverine monotherapy (Figure 4B and C). Meanwhile, papaverine monotherapy did not delay tumour growth in this xenograft model (Figure 4B). Recently, we reported that papaverine suppressed tumour growth in U87MG xenograft mice using a preventative effect study model (23). We determined that the anticancer efficacy of papaverine is related to the tumour volume at the stage of treatment. These findings suggest that papaverine can be used in combination with temozolomide to prevent the recurrence of GBM after resection. Indeed, standard treatment for GBM involves surgery/surgical resection of tumour along with radiation and adjuvant chemotherapy with temozolomide $(4,31)$. However, several limitations and risk factors are associated with radiation therapy, including the invasive nature of GBM, radiation-induced necrosis and neuronal damage, and radioresistance of some tumours $(4,32)$. Papaverine may be effective in reducing radioresistance and preventing adverse side-effects associated with radiation therapy for GBM.

Interestingly, we found that papaverine dramatically enhanced the radiosensitivity of temozolomide-resistant T98G GBM cells (Figure 5B). Benej et al. previously demonstrated that papaverine radiosensitizes A549 lung and EO771 breast cancer cells by inhibiting mitochondrial complex 1 (22). These results indicate that papaverine is a potential radiosensitizing agent that can be useful in treating various cancer types, including GBM. Importantly, papaverine was shown to enhance the reversible opening of the blood-brain barrier (33) and to mediate transient blood-brain barrier permeability (34). In conclusion, our findings suggest that papaverine can serve as an anticancer drug in GBM treatment.

\section{Conflicts of Interest}

None.

\section{Authors' Contributions}

Conceived and designed the experiments: AS. Performed the experiments: MI, AS, and MS. Analyzed the data: MI, AS, MS, YY, YA, KI, and ST. Wrote the article: AS.

\section{Acknowledgements}

The Authors would like to thank Dr. Takao Arai (Jikei University School of Medicine) for his helpful discussions. We would also like to thank Enago (www.enago.jp) for English language editing. This work was supported by a JSPS KAKENHI grant number 26670648 (T.A.) and an Education Research Fund for the Tokyo University of Science (AS and ST). The funding agencies had no role in designing this study, collecting and analyzing data, deciding to publish, or preparing the manuscript.

\section{References}

1 Laperriere N, Zuraw L and Cairncross G: Radiotherapy for newly diagnosed malignant glioma in adults: A systematic review. Radiother Oncol 64(3): 259-273, 2002. PMID: 12242114. DOI: 10.1016/s0167-8140(02)00078-6

2 Huse JT and Holland EC: Targeting brain cancer: Advances in the molecular pathology of malignant glioma and medulloblastoma. Nat Rev Cancer 10(5): 319-331, 2010. PMID: 20414201. DOI: $10.1038 / \mathrm{nrc} 2818$

3 Zhang J, Stevens MF and Bradshaw TD: Temozolomide: Mechanisms of action, repair and resistance. Curr Mol Pharmacol 5(1): 102-114, 2012. PMID: 22122467.

4 Batash R, Asna N, Schaffer P, Francis N and Schaffer M: Glioblastoma multiforme, diagnosis and treatment; recent literature review. Curr Med Chem 24(27): 3002-3009, 2017. PMID: 28521700 DOI: 10.2174/0929867324666170516123206

5 Ostrom QT, Gittleman H, Truitt G, Boscia A, Kruchko C and Barnholtz-Sloan JS: Cbtrus statistical report: Primary brain and other central nervous system tumors diagnosed in the united states in 2011-2015. Neuro Oncol 20(suppl 4): iv1-iv86, 2018. PMID: 30445539. DOI: 10.1093/neuonc/noy131

6 Sims GP, Rowe DC, Rietdijk ST, Herbst R and Coyle AJ: HMGB 1 and RAGE in inflammation and cancer. Annu Rev Immunol 28: 367-388, 2010. PMID: 20192808. DOI: 10.1146/annurev.immunol.021908.132603

7 Tang D, Kang R, Zeh HJ, 3rd and Lotze MT: High-mobility group box 1 and cancer. Biochim Biophys Acta 1799(1-2): 131-140, 2010. PMID: 20123075. DOI: 10.1016/j.bbagrm.2009.11.014

$8 \mathrm{Wu}$ L and Yang L: The function and mechanism of HMGB1 in lung cancer and its potential therapeutic implications. Oncol Lett 15(5): 6799-6805, 2018. PMID: 29725415. DOI: 10.3892/ol.2018.8215

9 He SJ, Cheng J, Feng X, Yu Y, Tian L and Huang Q: The dual role and therapeutic potential of high-mobility group box 1 in cancer. Oncotarget 8(38): 64534-64550, 2017. PMID: 28969092. DOI: $10.18632 /$ oncotarget.17885

10 Tamada K, Nakajima S, Ogawa N, Inada M, Shibasaki H, Sato A, Takasawa R, Yoshimori A, Suzuki Y, Watanabe N, Oyama T, Abe $\mathrm{H}$, Inoue $\mathrm{S}$, Abe T, Yokomizo T and Tanuma S: Papaverine identified as an inhibitor of high mobility group box $1 /$ receptor for advanced glycation end-products interaction suppresses high mobility group box 1-mediated inflammatory responses. Biochem Biophys Res Commun 511(3): 665-670, 2019. PMID: 30826057. DOI: $10.1016 /$ j.bbrc.2019.01.136

11 El-Far A, Munesue S, Harashima A, Sato A, Shindo M, Nakajima S, Inada M, Tanaka M, Takeuchi A, Tsuchiya H, Yamamoto H, Shaheen HME, El-Sayed YS, Kawano S, Tanuma SI and Yamamoto Y: In vitro anticancer effects of a RAGE inhibitor discovered using a structure-based drug design system. Oncol Lett 15(4): 4627-4634, 2018. PMID: 29541234. DOI: 10.3892/ol.2018.7902

12 Merck G: Vorläufige notiz über eine neue organische base im opium. Justus Liebigs Annalen der Chemie 66(1): 125-128, 1848. DOI: $10.1002 /$ jlac. 18480660121

13 Liu HM and Tu YK: The efficacy of papaverine administration by different routes for the treatment of experimental acute cerebral vasospasm. J Clin Neurosci 9(5): 561-565, 2002. PMID: 12383416.

14 Chappie TA, Humphrey JM, Allen MP, Estep KG, Fox CB, Lebel LA, Liras S, Marr ES, Menniti FS, Pandit J, Schmidt CJ, 
Tu M, Williams RD and Yang FV: Discovery of a series of 6,7dimethoxy-4-pyrrolidylquinazoline PDE10A inhibitors. J Med Chem 50(2): 182-185, 2007. PMID: 17228859. DOI: $10.1021 / \mathrm{jm} 060653 \mathrm{~b}$

15 Yildiz N, Gokkaya NK, Koseoglu F, Gokkaya S and Comert D: Efficacies of papaverine and sildenafil in the treatment of erectile dysfunction in early-stage paraplegic men. Int J Rehabil Res 34(1): 44-52, 2011. PMID: 20700057. DOI: 10.1097/ MRR.0b013e32833d6cb2

16 Goto T, Matsushima H, Kasuya Y, Hosaka Y, Kitamura T, Kawabe K, Hida A, Ohta Y, Simizu T and Takeda K: The effect of papaverine on morphologic differentiation, proliferation and invasive potential of human prostatic cancer lncap cells. Int J Urol 6(6): 314-319, 1999. PMID: 10404308. DOI: 10.1046/j.1442-2042.1999.00069.x

17 Shimizu T, Ohta Y, Ozawa H, Matsushima H and Takeda K: Papaverine combined with prostaglandin $\mathrm{E}_{2}$ synergistically induces neuron-like morphological changes and decrease of malignancy in human prostatic cancer LNCap cells. Anticancer Res 2O(2a): 761-767, 2000. PMID: 10810351.

18 Huang H, Li LJ, Zhang HB and Wei AY: Papaverine selectively inhibits human prostate cancer cell (PC-3) growth by inducing mitochondrial mediated apoptosis, cell cycle arrest and downregulation of NF-kappaB/PI3K/AKT signalling pathway. J Buon 22(1): 112-118, 2017. PMID: 28365943.

19 Afzali M, Ghaeli P, Khanavi M, Parsa M, Montazeri H, Ghahremani MH and Ostad SN: Non-addictive opium alkaloids selectively induce apoptosis in cancer cells compared to normal cells. DARU J Pharm Sci 23: 16, 2015. PMID: 25890335. DOI: 10.1186/s40199-015-0101-1

20 Sajadian S, Vatankhah M, Majdzadeh M, Kouhsari SM, Ghahremani MH and Ostad SN: Cell cycle arrest and apoptogenic properties of opium alkaloids noscapine and papaverine on breast cancer stem cells. Toxicol Mech Methods 25(5): 388-395, 2015. PMID: 25980655. DOI: 10.3109/15376516.2015.1045656.

21 Noureini SK and Wink M: Antiproliferative effect of the isoquinoline alkaloid papaverine in hepatocarcinoma HepG-2 cells - inhibition of telomerase and induction of senescence. Molecules 19(8): 11846-11859, 2014. PMID: 25111025. DOI: 10.3390/molecules 190811846

22 Benej M, Hong X, Vibhute S, Scott S, Wu J, Graves E, Le QT, Koong AC, Giaccia AJ, Yu B, Chen SC, Papandreou I and Denko NC: Papaverine and its derivatives radiosensitize solid tumors by inhibiting mitochondrial metabolism. Proc Natl Acad Sci USA 115(42): 10756-10761, 2018. PMID: 30201710. DOI: $10.1073 /$ pnas.1808945115

23 Inada M, Shindo M, Kobayashi K, Sato A, Yamamoto Y, Akasaki Y, Ichimura K and Tanuma SI: Anticancer effects of a non-narcotic opium alkaloid medicine, papaverine, in human glioblastoma cells. PLoS One 14(5): e0216358, 2019. PMID: 31100066. DOI: 10.1371/journal.pone.0216358

24 Ogino Y, Sato A, Uchiumi F and Tanuma SI: Cross resistance to diverse anticancer nicotinamide phosphoribosyltransferase inhibitors induced by FK866 treatment. Oncotarget 9(23): 1645116461, 2018. PMID: 29662658. DOI: 10.18632/oncotarget.24731
25 Ogino Y, Sato A, Uchiumi F and Tanuma SI: Genomic and tumor biological aspects of the anticancer nicotinamide phosphoribosyltransferase inhibitor fk866 in resistant human colorectal cancer cells. Genomics pii: S0888-7543(18)30663-3, 2018. PMID: 30582964. DOI: 10.1016/j.ygeno.2018.12.012

26 Fujimori H, Sato A, Kikuhara S, Wang J, Hirai T, Sasaki Y, Murakami Y, Okayasu R and Masutani M: A comprehensive analysis of radiosensitization targets; functional inhibition of DNA methyltransferase 3B radiosensitizes by disrupting DNA damage regulation. Sci Rep 5: 18231, 2015. PMID: 26667181. DOI: $10.1038 /$ srep 18231

27 Sato A, Itoh T, Imamichi S, Kikuhara S, Fujimori H, Hirai T, Saito S, Sakurai Y, Tanaka H, Nakamura H, Suzuki M, Murakami Y, Baiseitov D, Berikkhanova K, Zhumadilov Z, Imahori Y, Itami J, Ono K, Masunaga $\mathrm{S}$ and Masutani M: Proteomic analysis of cellular response induced by boron neutron capture reaction in human squamous cell carcinoma sas cells. Appl Radiat Isot 106: 213-219, 2015. PMID: 26302661. DOI: $10.1016 /$ j.apradiso.2015.08.001

28 Liu JK and Couldwell WT: Intra-arterial papaverine infusions for the treatment of cerebral vasospasm induced by aneurysmal subarachnoid hemorrhage. Neurocrit Care 2(2): 124-132, 2005. PMID: 16159054. DOI: 10.1385/NCC:2:2:124

29 Sayama CM, Liu JK and Couldwell WT: Update on endovascular therapies for cerebral vasospasm induced by aneurysmal subarachnoid hemorrhage. Neurosurg Focus 21(3): E12, 2006. PMID: 17029336.

30 Keyrouz SG and Diringer MN: Clinical review: Prevention and therapy of vasospasm in subarachnoid hemorrhage. Crit Care 11(4): 220, 2007. PMID: 17705883. DOI: $10.1186 / \mathrm{cc} 5958$

31 Mrugala MM: Advances and challenges in the treatment of glioblastoma: A clinician's perspective. Discov Med 15(83): 221-230, 2013. PMID: 23636139.

32 Iacob G and Dinca EB: Current data and strategy in glioblastoma multiforme. J Med Life 2(4): 386-393, 2009. PMID: 20108752.

33 Xue H, Wang H, Kong L and Zhou H: Opening blood-brain barrier by intracarotid infusion of papaverine in treatment of malignant cerebral glioma. Chin Med J (Engl) 111(8): 751-753, 1998. PMID: 11245034.

34 Bhattacharjee AK, Kondoh T, Nagashima T, Ikeda M, Ehara K and Tamaki N: Quantitative analysis of papaverine-mediated blood-brain barrier disruption in rats. Biochem Biophys Res Commun 289(2): 548-552, 2001. PMID: 11716508. DOI: $10.1006 /$ bbrc. 2001.6029 